\title{
ENABLING FLEXIBLE MANUFACTURING SYSTEMS BY USING LEVEL OF AUTOMATION AS DESIGN PARAMETER
}

\author{
Björn Johansson \\ Åsa Fasth \\ Johan Stahre \\ Production Systems \\ Product and Production Development \\ Chalmers University of Technology \\ Gothenburg, SE-412 94, SWEDEN
}

\author{
Juhani Heilala \\ Systems Engineering \\ VTT \\ Technical Research Centre of Finland \\ Espoo, FI-02044, FINLAND
}

\author{
Swee Leong \\ Y. Tina Lee \\ Frank Riddick \\ Manufacturing Systems Integration Division \\ National Institute of Standards and \\ Technology \\ Gaithersburg, MD 20889-8261, USA
}

\begin{abstract}
Handling flexibility in an ever changing manufacturing environment is one of the key challenges for a successful industry. By using tools for virtual manufacturing, industries can analyze and predict outcomes of changes before taking action to change the real manufacturing systems. This paper describes a simulation tool that can be used to study the effect of level of automation issues on the design of manufacturing systems, including their effect on the overall system performance, ergonomics, environment, and economic measures. Determining a suitable level of automation can provide a manufacturing system with the flexibility needed to respond to the unpredictable events that occur in factory systems such as machine failures, lack of quality, lack of materials, lack of resources, etc. In addition, this tool is designed to use emerging simulation standards, allowing it to provide a neutral interface for both upstream and downstream data sources.
\end{abstract}

\section{INTRODUCTION}

Discrete Event Simulation (DES) has proved itself to be an effective tool for complex processes analysis (Ericsson 2005, Banks et al. 2005). One problem with using DES is that it is often necessary to expend significant time and money to process input data from various data sources to ensure valid simulation results. Frequently, large amounts of time are needed for gathering and extracting data (Skoogh and Johansson 2007). Despite the fact that the data is hard to come by and use, simulation is a powerful problem solving tool for many industries today. One of the largest application areas for simulation is manufacturing systems, according to Law and McComas (1999). The first uses of this kind of simulation can be traced back to the early 1950's. Since then, the development of the field has been ongoing. However, simulations involving the integration of multidisciplinary parameters and their analysis is a more recent approach (Banks et al. 2005, Law and Kelton 2000). Simulation analysis can provide many production performance indicators. Some common aims of simulation analysis are to identify problem areas (such as bottlenecks and choke points), to quantify or optimize production system performance measures (such as throughput under average and peak loads, resource and labor utilization, queuing levels at work locations, work-in-process levels, etc.), and to evaluate production scheduling issues (such as schedule effectiveness, material handling alternatives, shift definition, effective staffing levels, queuing rules for machines, process routing alternatives, etc.). Discrete event Simulation, in the context of this paper, will serve as a platform for Level of Automation (LoA) analysis.

\subsection{Level of Automation}

Modern manufacturing systems normally include complex technical equipment as well as skilled human operators. An important design issue is the allocation of work tasks between humans and technology when developing and changing such systems. Often, such decisions are considered in a more or less binary manner; that is, either a system is automated or it is manual. Sheridan defines the decision as "allocate to the human the tasks best suited to the human, allocate to automation the tasks best suited to it" (Sheridan 1995). This is based on Fitts' MABA-MABA list published in 1951(Fitts 1951).

Recent research by Frohm (2008) and Harlin et al. (2006) suggests that careful consideration and controlled change of the LoA (i.e., using a gradual increase or decrease of the number of automated tasks) may increase productivity and flexibility in many manufacturing systems. Lowering the LoA in a system may have the downside of increasing operation times. However, the increased number of operations performed manually will have a positive influence on system flexibility and provide for rapid disturbance handling. Experiences from research of computer and aircraft control systems operation suggest 
that dynamic but controlled adjustment of the levels of automation in a system may be a powerful tool for semi-automated system control (Frohm 2008). In Parasuraman, Sheridan, and Wickens (2000), it is also suggested that the LoA can be assessed and analyzed by decomposing semi-automated tasks into physical and cognitive components. This enables a more detailed design of physical tasks and decision support tools. The LoA has natural implications on the ergonomic features of a work situation, with respect to physical ergonomics as well as cognitive ergonomics issues.

The concept Levels of Automation (LoA) used here has been defined by Frohm (Frohm 2008) as "the allocation of physical and cognitive tasks between humans and technology, described as a continuum ranging from totally manual to totally automatic". The level of automation for mechanical activities is referred to as the mechanical LoA, while the level of automation for cognitive activities is called information LoA. Table 1 shows the reference scale for different Levels of Automation. The mechanical and information level of automation aspects of tasks may be considered together, where the level is chosen from a7x7 matrix of 49 possibilities. The 49 possible solutions may then be limited to a relative max and min level for the different scales. This creates what is called a SoPI (Square of Possible Solutions), and it is created based on the company's goal function, ergonomic, and environmental issues, investment cost etc. (Fasth, Stahre, and Deckner 2008). These possible solutions is then used as an input in the SIMTER (Simulation-based production development tool with ergonomic and environmental aspects for traditional manufacturing industries tool) tool (Lind et al. 2008b).

Table 1. Level of Automation scales for mechanized and computerized task (Frohm 2008)

\begin{tabular}{|c|c|c|}
\hline LoA & $\begin{array}{l}\text { Mechanical and Equipment } \\
\text { Level of Automation (Mechanical LoA) }\end{array}$ & $\begin{array}{l}\text { Information and Control } \\
\text { Level of Automation (Information LoA) }\end{array}$ \\
\hline 1 & $\begin{array}{l}\text { Totally manual - Totally manual work, no tools are } \\
\text { used, only the users own muscle power. E.g., The us- } \\
\text { er's own muscle power }\end{array}$ & $\begin{array}{l}\text { Totally manual - The user creates his/her own under- } \\
\text { standing of the situation and develops his/her course of } \\
\text { action based on his/her earlier experience and know- } \\
\text { ledge. E.g., The user's earlier experience and know- } \\
\text { ledge }\end{array}$ \\
\hline 2 & $\begin{array}{l}\text { Static hand tool - Manual work with support of a } \\
\text { static tool. E.g., Screwdriver }\end{array}$ & $\begin{array}{l}\text { Decision giving - The user gets information about what } \\
\text { to do or a proposal for how the task can be achieved. } \\
\text { E.g., Work order }\end{array}$ \\
\hline 3 & $\begin{array}{l}\text { Flexible hand tool - Manual work with the support } \\
\text { of a flexible tool. E.g., Adjustable spanner }\end{array}$ & $\begin{array}{l}\text { Teaching - The user gets instruction about how the task } \\
\text { can be achieved. E.g., Checklists, manuals }\end{array}$ \\
\hline 4 & $\begin{array}{l}\text { Automated hand tool - Manual work with the sup- } \\
\text { port of an automated tool. E.g., Hydraulic bolt driver }\end{array}$ & $\begin{array}{l}\text { Questioning - The technology questions the execution, } \\
\text { if the execution deviates from what the technology con- } \\
\text { siders suitable. E.g., Verification before action }\end{array}$ \\
\hline 5 & $\begin{array}{l}\text { Static machine/workstation - Automatic work by a } \\
\text { machine that is designed for a specific task. E.g., } \\
\text { Lathe }\end{array}$ & $\begin{array}{l}\text { Supervision - The technology calls for the users' atten- } \\
\text { tion, and directs it to the present task. E.g., Alarms }\end{array}$ \\
\hline 6 & $\begin{array}{l}\text { Flexible machine/workstation - Automatic work by } \\
\text { a machine that can be reconfigured for different } \\
\text { tasks. E.g., CNC machine }\end{array}$ & $\begin{array}{l}\text { Intervene - The technology takes over and corrects the } \\
\text { action, if the executions deviate from what the technol- } \\
\text { ogy considers suitable. E.g., Thermostat }\end{array}$ \\
\hline 7 & $\begin{array}{l}\text { Totally automatic - Totally automatic work. The } \\
\text { machine solves all deviations or problems that occur } \\
\text { by itself. E.g., Autonomous systems }\end{array}$ & $\begin{array}{l}\text { Totally automatic - All information and control are } \\
\text { handled by the technology. The user is never involved. } \\
\text { E.g., Autonomous systems }\end{array}$ \\
\hline
\end{tabular}

A modern manufacturing system is an integrated combination of processes, machine systems, people, organizational structures, information flows, control systems, and computers whose purpose is to achieve economic product manufacture with internationally competitive performance. Employing automation, and the selection of the appropriate level of automation, is usually a strategy that depends on many variables, starting from the product itself. The manufacture of some products might be beyond the capabilities of a human operator, due to size, process or quality reasons. Other common factors in deciding to employ automation include the process technology used, the amount of process flexibility needed, the type of equipment and technology level available, the physical factory layout, the factory's geographic location, the factory size, and the planned production capacity. Groover (2001) lists a number of reasons for automation:

- To increase labor productivity.

- To reduce labor cost.

- To mitigate the effects of labor shortages.

- To reduce or eliminate routine manual and clerical tasks.
- To improve worker safety.

- To improve product quality.

- To reduce manufacturing lead time.

- To accomplish processes that cannot be done manually. 
Proceedings of the 2009 Winter Simulation Conference

M. D. Rossetti, R. R. Hill, B. Johansson, A. Dunkin and R. G. Ingalls, eds.

- To avoid the high cost of not automating.

Some of these may be considered top-down reasons, i.e., they are 'forced' on the operations level from top management, while others are more likely to emanate from bottom-up, i.e., they are initiated by other than business related reasons. Engineers and managers need to justify the decisions on whether to automate or not to automate. Findings from (Fasth and Stahre 2008) show that a majority of the companies that have been analyzed need to change their cognitive automation level and improve their production logistics before changing the mechanical LoA. To be able to distinguish the most advantageous cognitive and mechanical LoA for a specific task or operation, a method called DYNAMO++ has been developed. This method allows companies to analyze their current and the future systems in a structured way (Fasth and Stahre 2008, Fasth, Stahre, and Deckner 2008). Discrete event simulation is a suitable tool for the analysis of effects and thus supports effective decision making. The normal performance indicators, cost, quality, and time, are always present. Determining the appropriate level of automation should have positive effects on manufacturing performance. The LoA of a factory can greatly impact its operating cost (labor and other variable cost) as well as its fixed costs (such as investment in equipment). To determine the appropriate LoA, all the cost related to the planned life cycle of the equipment should be analyzed. Performing a total cost of ownership analysis integrated with simulation studies is shown in Heilala et al. (2006) and Heilala et al. (2007).

\subsection{Core Manufacturing Simulation Data}

The Core Manufacturing Simulation Data (CMSD) specification (SISO 2009) is intended to define a neutral format for the exchange of data between simulations and other manufacturing applications. The CMSD specification is being developed by NIST under the auspices of the Simulation Interoperability Standards Organization (SISO). Over the last few of years, several projects involving researchers from different industries have been undertaken where the draft CMSD specification (SISO 2007 ) is used to integrate manufacturing applications. Examples of these projects can be found in Kibira and McLean (2007), Johansson et al. (2007), McLean et al. (2007), Balderud and Olofsson (2008), Johansson and Zachrisson (2006), Riddick and Lee (2008).

The CMSD specification was developed to address interoperability issues related to information definition and exchange as it provides a neutral framework for modeling manufacturing information, with an emphasis the information needed for manufacturing simulation. Information coding and representation problems increase the time and effort required to construct simulations and limit the application of simulation technology in manufacturing, especially for smaller companies. Such problems often render the data used in one simulation unusable in other simulations, which might have been constructed for a different purpose. In addition, manufacturing simulation data is difficult to exchange between different simulation applications and other manufacturing applications.. The Core Manufacturing Simulation Data specification is intended to be a neutral data format for addressing interoperability problems such as these. CMSD is defined as an information model using the Unified Modeling Language (UML) with a mapping to an exchangeable eXtensible Markup Language (XML) format..

The CMSD information model describes essential entities in the manufacturing domain and relationships between those entities needed to create manufacturing-oriented simulations. This specification facilitates the exchange of information between manufacturing-oriented simulations and other manufacturing applications such as process planning, scheduling, inventory management, production management, and plant layout. Six UML packages group related data (SISO 2009). These packages are:

- Layout

- Part Information

- Support

- Resource Information

- Production Operations

- Production Planning.

Leong, Lee, and Riddick (2006) give a detailed description of these packages. The draft specification (SISO 2009) provides the complete specification of CMSD. The formal balloting process for this specification is slated to begin in late 2009.

\section{SIMTER TOOL}

The SIMTER tool provides a means to perform joint analysis of environmental impact calculations in combination with discrete event simulation, and to perform virtual analysis of level of automation impacts in combination with ergonomic considerations. Information about some parts of the SIMTER tool have recently been published in Lind et al. 2008a; Heilala et al. 2008; Fasth, Stahre, and Deckner 2008; Lind et al. 2008b. The SIMTER tool is made up of three sub-tools: Ergonomics, En- 
vironment, and Level of Automation. The subject of this paper is the tool for Level of Automation analysis. The sub-tools are connected as shown in Figure 1.

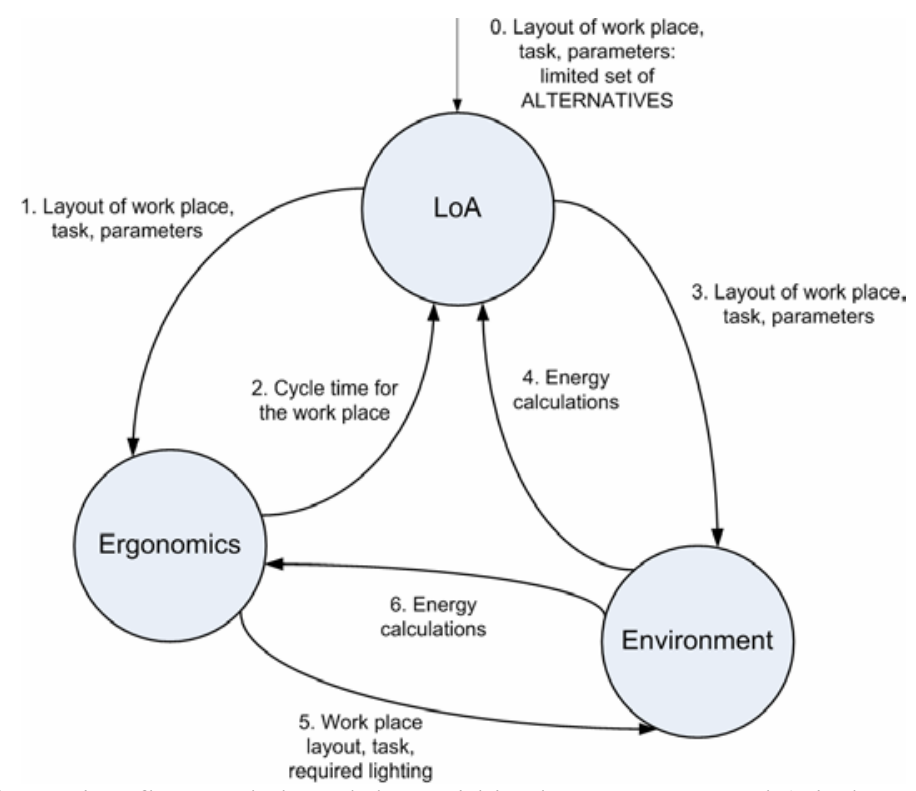

Figure 1: Information flow and shared data within the SIMTER-tool (Lind et al. 2008b)

To avoid using several different simulation software packages and to reduce the total cost of the SIMTER tool, early on in the project it was decided to exploit commercial software that included both factory and robotic simulation features. The package chosen was 3DCreate by Visual Components (Visual Components 2008). It is a component-based simulation software package with three-dimensional (3D) capabilities that enable fast design and system analysis. It comes with a selection of pre-engineered re-usable sub-model components, and new components can also be created.

An advantage of using 3D simulation software in the SIMTER tool is that it provides for a more realistic visualization of the system, which improves communication. Support for 3D visualization is also needed in ergonomic analysis and robotic work-cell design.

The Visual Components software is extendable and supports plug-in application development. An example of a plug-in is the digital man model OSKU (Helin et al. 2007), which was further refined in the SIMTER project. Another example is the Total Cost of Ownership (TCO) (Heilala, Helin, and Montonen 2006; Heilala et al. 2007) analysis methodology. It is also possible to integrate external applications with the simulation components, and to read and write data from/to spreadsheets or other external files. During the SIMTER project, implementation plug-ins on the 3DCreate platform for each of the three SIMTER sub-areas: ergonomics, environmental impacts, and LoA was made. The ergonomics plug-in can be used to analyze physical workload of an operator over time, using OWAS (Ovako Working posture Analysis System), RULA (Rapid Upper Limb Assessment) and Ergokan measures, as described in Lind et al. (2008a), as well as checklist for non workload related issues such as light, hazardous chemicals, social environment etc. The environmental impacts plug-in can be used to analyze Lifecycle assessment data which is refined and calculated over time during simulation runs. The database used is a public EU Lifecycle Assessment (LCA) database as described by Heilala et al. (2008). More details about the environmental impacts plug-in are described in Heilala et al. (2008). Level of Automation plug-in will be described in the next section.

\section{LEVEL OF AUTOMATION AS A DESIGN PARAMETER}

By developing a simulation environment that can utilize CMSD as data source for analyzing Level of Automation, a neutral integration and development platform has been achieved. When the data have been translated into the CMSD data format, the data can be used either for Level of Automation analysis in current software or as input data for any other manufacturing system with an CMSD-compatible interface.

An illustrative 'Toy case' scenario is described below. Since this tool is still in development, it has not been tested in a real world environment. However pilot testing of this tool is ongoing at a real world production facility. 


\subsection{System description}

The illustrative prototype simulation model was built using existing simulation model library components. The SIMTER "ToyCase" has 5 manufacturing processing steps: assembly (in an automated and/or manual workstation), inspection (in an automated and/or manual workstation), painting, drying, and packing (in an automated and/or manual workstation). Figure 2 is an example of a generic and representative process flow diagram. Figure 3 shows the prototype simulation model.

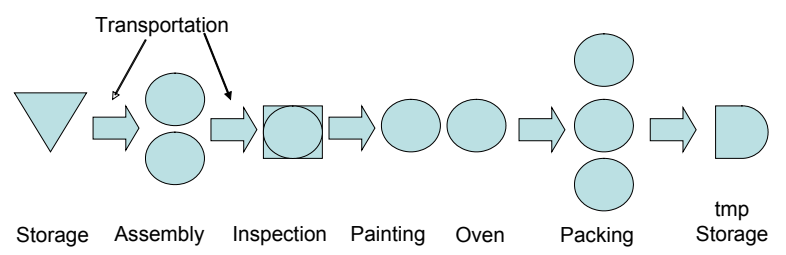

Figure 2: Process flow of case example

The product consists of three parts made from plastics, wood, and iron. The simulation model shown in Figure 3 may be unrealistic or infeasible in real life, but it is a good case study for testing the viability of utilizing different selections of automation levels as a design parameter.

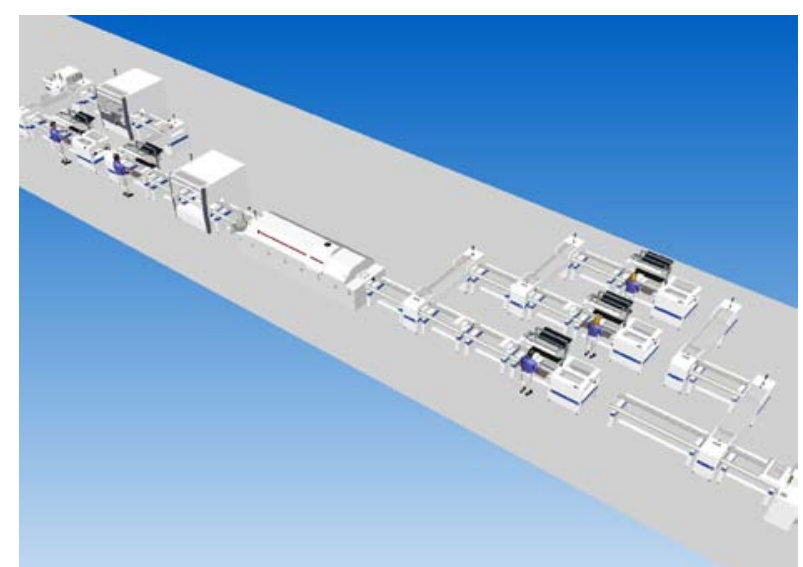

Figure 3: Simulation model

\subsection{Inputs/outputs}

The unique feature enabled by the SIMTER Level of Automation sub-tool is that it has 49 predefined automation levels (see figure 4), all according to the Level of Automation Scale developed by Frohm (2008), which include both information and mechanical level of automation. To demonstrate how the system works, LoA mechanical level 1 and information level 3 are selected. LoA mechanical level 1 means it does not use any tools, and LoA information level 3 means information conveyed through written instructions. Based on the level of automation selected, specific settings will then be use to run the model. The model will achieve specific behavior at the workstation. The resultant output parameters such as lead times, throughput rates, and utilizations are the same as ordinary discrete event simulation software. The SIMTER environmental sub-tool uses lifecycle assessment data to provide environmental performance indications, such as aggregated $\mathrm{CO}_{2}$ emissions, energy consumption per product produced, per each resource, and total for the whole system. The ergonomic sub-tool performs ergonomic analysis for the workers at the workstations, using checklists and ergonomic measures during simulation run as provided by RULA and OWAS.

Since human operators and machines perform differently in many ways, LoA parameters affect the input data which needs to be defined at the workstation and/or task level. Examples of the input data are process cycle time and its variations, availability, and operating time. Also note that human performance variation is one of the most difficult system parameters to model, since humans are more or less chaotic in their behaviors. Factors that exacerbate the situation include the expected quality level, the aptitude, the skill level of the human operator, the expected error rate, and social interaction skills. 


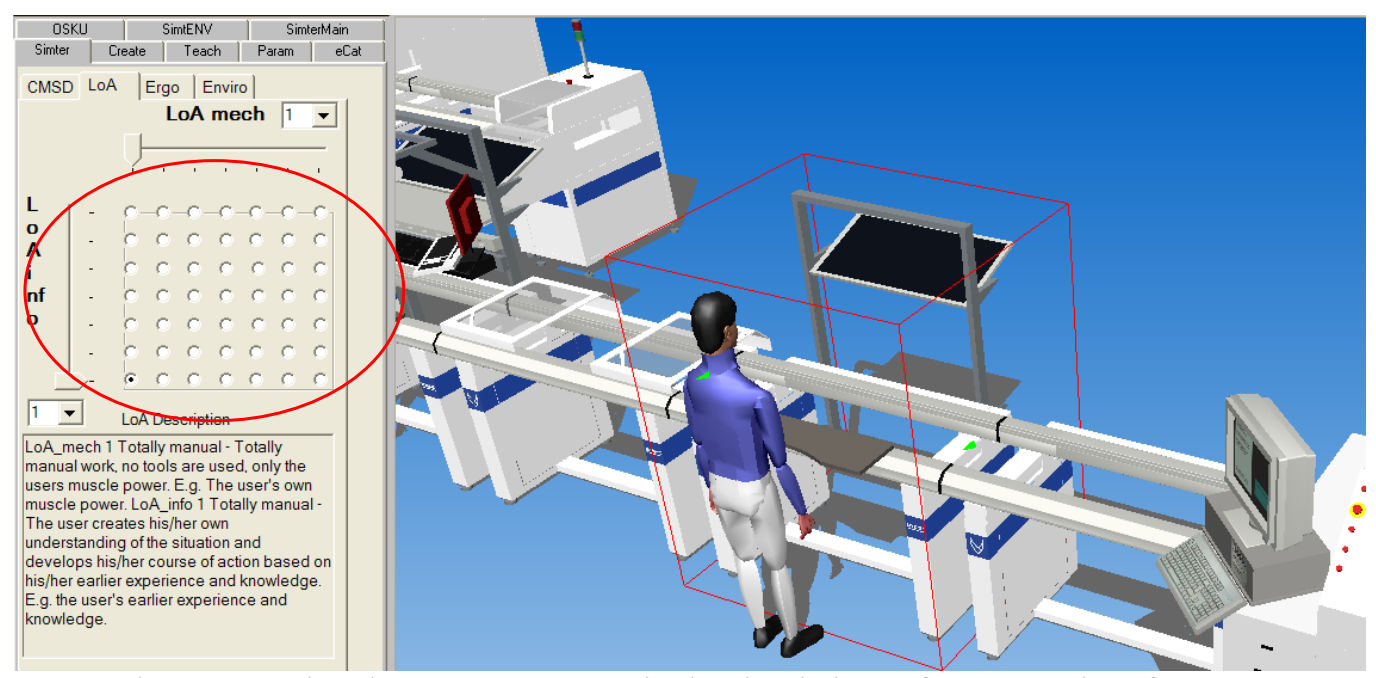

Figure 4: Setting the LoA parameters in the simulation software user interface

\subsection{Scenarios}

By altering the input parameters of the mechanical level and information level in the Level of Automation simulation run we can see how it affects the performance of the system. Fixed and flexible cost of the system will have different values and will also result in different payback times. Even if the managers and engineers do not have absolute accurate parameters in the simulation analysis, a feasible comparison between scenarios can be done. System performance can be studied, evaluated, and decision making can be done by using same or similar input data for all scenarios with different system layouts, operating principles, and level of automation. Naturally accuracy and quality of input data must be taken into account, while evaluating simulation results.

Typically scenario evaluation is an iterative process. There are interactions between the SIMTER sub tools as shown in Figure 1, for example mechanical LoA decision has a direct effect on ergonomics. Bad ergonomics analysis results might indicate that there is a need to change workstation layout, increase mechanical LoA, and use machine muscle to reduce fatigue for human operators. Similarly, capability of the human operator can be enhanced with suitable hoisting devices or other tools supporting the task to be performed. On the other hand, if those devices are electrically powered, it might influence on the environmental performance measures.

\section{DISCUSSION}

By introducing the LoA as a design parameter consideration we can quickly achieve results from the simulation whether a solution is feasible or not while combining manual, semi-automated, and automated work. The choice of automation level will also have an influence on ergonomics as well as on environmental effects. This provides the opportunity for generating richer and more detailed analysis results as compared to traditional methods, where the engineer has to evaluate one parameter at a time and keep different input parameters from influencing each other while examining output data. Using the SIMTER tool comes with additional data requirements, but by using CMSD as the input data format this burden should be lessened considerably.

\section{FUTURE RESEARCH}

Additional efforts are needed to populate the Level of Automation data for the tool. For now test data set is used as input data for each level of automation. A database with sound data for each level of automation can be achieved by collecting data from real case studies. The first real case study started in early March 2009 at an automotive manufacturer in Sweden. The next upcoming project within this field is being specified as of now in order to continue the development of cross disciplinary objective functions for manufacturing system design, such as considering environment, ergonomics and monetary units within the same analysis. 
A Discrete event simulation tool for analyzing Level of Automation is presented. The tool can be used to analyze how different levels of automation influence the performance of a manufacturing system. The input data interface is generic and based on CMSD, which is a standardization effort being undertaken by National Institute of Standards and Technology.

Using Level of Automation as a design parameter in discrete event simulation seems to be feasible, however further research and implementation tests need to be done in order to prove feasibility. The most suitable manufacturing area for such a case study is probably an automotive assembly line, where the Level of Automation can be changed for specific assembly tasks. This facilitates collection of test data sets for future level of automation research. This type of assembly systems would also suit for different Level of Automation input since each task can be studied repetitively.

\section{ACKNOWLEDGMENTS AND DISCLAIMER}

The authors would like to express gratitude to the SIMTER project's industrial partners. Also, we acknowledge the funding from TEKES (Finnish Funding Agency for Technology and Innovation.) and VINNOVA (Swedish Agency for Innovation Systems, integrates research and development in technology, transport and working life.) through the MERA-program. The work described was also funded by the United States Government and is not subject to copyright. No approval or endorsement of any commercial product by the National Institute of Standards and Technology is intended or implied.

\section{REFERENCES}

Balderud, J., and A. Olofsson. 2008. A Plug-in Based Software Architecture for Generic Data Management, Master's thesis, Department of Computer Science and Engineering. Chalmers University of Technology, Gothenburg.

Banks, J., J. S. Carson, B. L. Nelson, and D. M. Nicol. 2005. Discrete-event system simulation. 4th ed. Upper Saddle River, New Jersey: Prentice-Hall, Inc.

Ericsson, U. 2005. Discrete Event Simulation, The Truth. Ph.D. thesis, Department of Production Engineering, Chalmers University of Technology, Sweden.

Fasth, A., and J. Stahre. 2008. Does Levels of Automation need to be changed in an assembly system? - A case study. The 2nd Swedish Production Symposium (SPS). Stockholm, Sweden.

Fasth, Å., J. Stahre, and K. Deckner. 2008. Measuring and analysing Levels of Automation in an assembly system. The 41st CIRP conference on manufacturing systems Tokyo, Japan.

Fitts, P. 1951. Human engineering for an effective air navigation and traffic control system. Columbus, OH, Ohio state university.

Frohm, J. 2008. Levels of Automation in Production Systems, Department of Production Systems, Chalmers University of Technology, Göteborg, Sweden (Ph.D. Thesis).

Groover, M. P. 2001. Automation, Production Systems, and Computer-Integrated Manufacturing, second ed. Prentice-Hall, Englewood Cliffs, NJ, USA.

Harlin, U., J. Frohm, M. Berglund, and J. Stahre. 2006. Towards Efficient Automation Implementation", In Proceedings of the 9th symposium IFAC on "Automated Systems Based on Human Skills and Knowledge", Mayer, F. and Stahre, J. (Eds.) 22-24 May, Nancy, France.

Heilala, J., K. Helin, and J. Montonen. 2006. Total cost of ownership analysis for modular final assembly systems. In International Journal of Production Research. Vol. 44 (2006) No: 18 - 19, 3967 - 3988

Heilala, J., V. Saija, H. Tonteri, J. Montonen, B. Johansson, J. Stahre, and S. Lind. 2008. Simulation-Based Sustainable Manufacturing System Design, In Proceedings of the 2008 Winter Simulation Conference, eds. S. J. Mason, R. R. Hill, L. Mönch, O. Rose, T. Jefferson, and J. W. Fowler, 1922-1930, Piscataway, New Jersey: Institute of Electrical and Electronics Engineers, Inc.

Heilala, J., O. Väätäinen, J. Montonen, T. Laaksonen, and H. Kulmala. 2007. Decision Support and Simulation Methods For Assembly System Sales Engineers. The 6th EUROSIM Congress, Ljubljana, Slovenia. 9th - 13th September 2007.

Helin, K., J. Viitaniemi, S. Aromaa, J. Montonen, T. Evilä, S. Leino, and T. Määttä. 2007. OSKU Digital Human Model in the Participatory Design Approach. A New Tool to Improve Work Tasks and Workplaces. VTT Working Papers VTTWORK-83. Available at $<$ http://www.vtt.fi/inf/pdf/workingpapers/2007/W83.pdf > . [accessed April 13, 2009]

Johansson, M., and R. Zachrisson. 2006. Modeling automotive manufacturing process. Master's thesis. Department of Product and Production development. Chalmers University of Technology, Gothenburg.

Johansson, M., S. Leong, Y. T. Lee, F. Riddick, G. Shao, B. Johansson, A. Skoogh, and P. Klingstam. 2007. Generic Simulation of Automotive Assembly for Interoperability Testing, In Proceedings of the 2007 Winter Simulation Conference, 
eds. S. G. Henderson, B. Biller, M.-H. Hsieh, J. Shortle, J. D. Tew, and R. R. Barton, 1035-1043, Piscataway, New Jersey: Institute of Electrical and Electronics Engineers, Inc.

Kibira, D., and C. McLean. 2007. Generic Simulation of Automotive Assembly for Interoperability Testing, In Proceedings of the 2007 Winter Simulation Conference, eds. S. G. Henderson, B. Biller, M.-H. Hsieh, J. Shortle, J. D. Tew, and R. R. Barton, 1035-1043. Piscataway, New Jersey: Institute of Electrical and Electronics Engineers, Inc.

Law, A. M., and M. G. McComas. 1999. Simulation of Manufacturing Systems, In Proceedings of the 1999 Winter Simulation Conference, IEEE, Phoenix, pp. 56-59.

Law, A. M., and W. D. Kelton. 2000. Simulation modeling \& analysis. 3rd ed. New York: McGraw-Hill, Inc.

Leong, S, Y. T. Lee, and F. Riddick. 2006. A Core Manufacturing Simulation Data Information Model for Manufacturing Applications. Simulation Interoperability Workshop, Simulation Interoperability and Standards Organization, September 10-15, 2006, Orlando.

Lind, S., B. Krassi, J. Viitaniemi, S. Kiviranta, J. Heilala, and C. Berlin. (2008a). Linking Ergonomics Simulation to Production Process Development, In Proceedings of the 2008 Winter Simulation Conference, eds. S. J. Mason, R. R. Hill, L. Mönch, O. Rose, T. Jefferson, and J. W. Fowler, 1968-1973, Piscataway, New Jersey: Institute of Electrical and Electronics Engineers, Inc.

Lind, S., B., Krassi, B. Johansson, J. Viitaniemi, J. Heilala, J. Stahre, S. Vatanen, Å. Fasth, and C. Berlin. 2008b. SIMTER: A Production Simulation Tool for Joint Assessment of Ergonomics, Level of Automation and Environmental Impacts. The 18th International Conference on Flexible Automation and Intelligent Manufacturing (FAIM 2008), June 30 - July 2, 2008.

McLean, C., S. Jain, F. Riddick, and Y. T. Lee. 2007. A simulation Architecture for Manufacturing Interoperability Testing In Proceedings of the 2007 Winter Simulation Conference, S. G. Henderson, B. Biller, M.-H. Hsieh, J. Shortle, J. D.

Parasuraman, R., T. B. Sheridan, and C. D Wickens. 2000. A Model for Types and Levels of Human Interaction with Automation, IEEE Transactions on System, Man, and Cybernetics - Part A: Systems and Humans Vol. 30 (3), pp. 286-296.

Riddick, F, and Y. T. Lee. 2008. Representing Layout Information in the CMSD Specification, In Proceedings of the 2008 Winter Simulation Conference, eds. S. J. Mason, R. R. Hill, L. Mönch, O. Rose, T. Jefferson, and J. W. Fowler, Piscataway, New Jersey: Institute of Electrical and Electronics Engineers, Inc.

Sheridan, T. B. 1995. Human centred automation: oxymoron or common sense? IEEE, 6.

SISO. 2007. Draft core manufacturing simulation data information model part 1: UML model. CMSD Product Development Group, Simulation Interoperability Standards Organization. Available via $<$ http://discussions.sisostds.org/default.asp?action=9\&boardid=2\&read=39532\&fid=24> [accessed April 13, 2009]

SISO. 2009. Pending standard: Core Manufacturing Simulation Data: UML model, SISO-STD-008-2009. CMSD Product Development Group, Simulation Interoperability Standards Organization. Available at http://discussions.sisostds.org/file.asp?file=CMSDBallotingDraft\%2DReviewVersion\%2Epdf [accessed July 28, 2009]

Skoogh, A., and B. Johansson. 2007. Time-consumption Analysis of Input Data Activities in Discrete Event Simulation Projects, In Proceedings of the Swedish Production Symposium 2007, Gothenburg, Sweden.

Visual Components. $<$ http://www.visualcomponents.com> . [accessed April 13, 2009]

\section{AUTHOR BIOGRAPHIES}

BJÖRN JOHANSSON is an Assistant Professor at Division of Production Systems, Department of Product and Production Development, Chalmers University of Technology, currently also a guest researcher at National Institute of Standards and Technology. His research interest is in the area of discrete event simulation for manufacturing industries, modular modeling methodologies, environmental effects modeling, software development, user interfaces, and input data architectures. His email address is $<$ bjorn.johansson@chalmers.se $>$.

ÅSA FASTH is a PhD student at Division of Production Systems, Department of Product and Production Development, Chalmers University of Technology. Her research includes topics on Level of Automation, for example how Level of Automation can be used as a design parameter when building new production lines of modifying existing ones. Her email address is <asa.fasth@chalmers.se>.

JOHAN STAHRE is an associate professor and the head of the Division of Production Systems at Chalmers University. His research focus is on human supervisory control in semi-automated manufacturing systems, Level of Automation and Sustainable production. His email address is $<$ johan.stahre@chalmers.se $>$. 
JUHANI HEILALA is a senior research scientist at VTT, the Technical Research Centre of Finland. He has an MSc from the Department of Mechanical Engineering at Oulu University. He has 20 years' experience in robotics and production system development. In past projects simulation technology have been the key technology. His current research interest includes expanding simulation and modeling from system design and analysis methods to simulation-based manufacturing operation planning and integration of production system simulation with other analysis methods. A list of publications is available at $<$ http://www.vtt.fi/vtt_search.jsp?lang=en> using the author's name. His e-mail address is $<$ juhani.heilala@vtt.fi $>$.

SWEE LEONG is a senior manufacturing engineer in the Manufacturing Simulation and Modeling Group at the National Institute of Standards and Technology (NIST) Manufacturing System Integration Division since 1994. Prior to joining NIST, he worked at Ford Motor Company, John Deere, and IBM on different factory automation projects. His research interests are in modeling and simulation activities for the manufacturing industries and engineering tools integration. Currently, Swee manages the Simulation Standards Consortium at NIST. He is Chairman of the Core Manufacturing Simulation Data Product Development Group. He received a Bachelor and Master Degrees in Industrial Engineering from Purdue University in West Lafayette, Indiana. $\mathrm{He}$ is a senior member of the Society of Manufacturing Engineers. His e-mail address is $<$ leong@nist.gov>.

Y. TINA LEE is a computer scientist in the Manufacturing Simulation and Modeling Group at NIST. She joined NIST in 1986. Her major responsibility in recent years has been to develop information models to support various manufacturing application areas. Previously she worked at Contel Federal Systems and Sperry Corporation. Her e-mail address is $<$ leet@cme.nist.gov>.

FRANK RIDDICK is a computer scientist in the Manufacturing Simulation and Modeling Group in The National Institute of Standards and Technology (NIST) Manufacturing Systems Integration Division. He has participated in research and authored several papers relating to manufacturing simulation integration and product data modeling. He holds a Master's Degree in Mathematics from Purdue. His email address is <riddick@nist.gov>. 